\title{
Comparison of Speech Perception Abilities of Children using Bimodal Hearing with Children using Cochlear Implant Alone
}

\author{
Gauri Belsare ${ }^{1}$ Sharda Sarda ${ }^{1}$ Prakash Bhardwaj \\ ${ }^{1}$ School of Audiology and Speech Language Pathology, Bharati \\ Vidyapeeth Deemed to be University, Pune, Maharashtra, India \\ 2Department of ENT, Shaheed Hasan Khan Mewati Government \\ Medical College, Nalhar, Nuh, Haryana, India \\ ${ }^{3}$ Department of ENT, Bharati Vidyapeeth Deemed to be University, \\ Pune, Maharashtra, India
}

Ann Otol Neurotol:2021;3:72-76
Sai Belsare ${ }^{3}$

\begin{abstract}
Address for correspondence Gauri Belsare, MS (ENT), Cochlear Implant Program, School of Audiology and Speech Language Pathology, Bharati Vidyapeeth Deemed to be University, Pune, Maharashtra, India (e-mail: gsbelsare@gmail.com).
\end{abstract}

\begin{abstract}
Keywords

- hearing loss

- inner ear conditions

- otology

Introduction There are very few studies comparing speech perception abilities of children using bimodal hearing over monaural cochlear implant and factors related to benefit of bimodal hearing. The aim of this study is to compare speech perception abilities of children using bimodal fitting versus children using cochlear implant alone and explore factors related to benefit of bimodal hearing.

Materials and Methods In the present study, 20 cochlear implantees with the hearing age range of 3 to 8 years were included. Speech perception performance was assessed by means of Parent's Evaluation of Aural/Oral Performance of Children scale and early speech perception (ESP) test: Pattern Perception Words, Monosyllabic Words, Bisyllabic, and Trisyllabic Words Identification test. ESP test was carried out in two conditions cochlear implant with hearing aid in opposite ear ( $\mathrm{ClHA})$, bimodal, and cochlear implant $(\mathrm{Cl})$ alone. Aided audiometry was also carried out in above mentioned two conditions.

Results and Discussion On aided audiometry test, aided thresholds were improved by 5 to $6 \mathrm{~dB}$ in $\mathrm{ClHA}$ condition as compared to $\mathrm{Cl}$ alone condition in 14 out of 20 children. Whereas on speech perception test, there was a significant improvement of 15 to $20 \%$ on domains of ESP test in these children. Factors such as implant age, chronological age, and number of hours of hearing aid usage were not significantly associated with benefit. Nevertheless aided threshold at $4,000 \mathrm{~Hz}$ was found to be significantly associated with bimodal benefit.

Conclusion Bimodal hearing is beneficial in most of the children than monaural hearing through cochlear implant.
\end{abstract}

\section{Introduction}

Binaural hearing is hearing from both ears, which is an ideal hearing condition for every individual. It has many advantages such as enhanced understanding of speech in noisy situations, localization, and overall reduced listening efforts as compared with monaural hearing. Bimodal hearing means hearing from two ears but with different mode of stimulation such as electrical stimulation from cochlear implant in one ear and acoustical stimulation on other ear using hearing aid for the same individual. ${ }^{1-3}$ In such condition, a hearing aid can provide access to low frequency acoustic cues and fine structure information which are not completely available through the cochlear implant. Past
Published online

September 2, 2020
DOI https://doi.org/

10.1055/s-0040-1715930

ISSN 2581-9607.
(C)2020. Indian Society of Otology.

This is an open access article published by Thieme under the terms of the Creative Commons Attribution-NonDerivative-NonCommercial-License, permitting copying and reproduction so long as the original work is given appropriate credit. Contents may not be used for commercial purposes, or adapted, remixed, transformed or built upon. (https://creativecommons.org/licenses/by-nc-nd/4.0/).

Thieme Medical and Scientific Publishers Pvt. Ltd. A-12, 2nd Floor, Sector 2, Noida-201301 UP, India 
literature report that bimodal listening can improve speech recognition performance in quite as well noisy conditions, and may be helpful when true binaural hearing cannot be provided by means of two implants due to reasons like financial constrain or unwilling ness of parents to undergo two implants. 4,5

Gordon et al reported that children listening through bimodal condition appears to be hearing in the middle of their head rather than in one ear. ${ }^{6}$ Moreover, researchers suggested that use of both devices worn together offered better sound quality and localization ability. Children using bimodal listening initiate more conversation, understand more of what's being said, and require less repetition. ${ }^{7.8}$

Present study addresses the question of whether bimodal stimulation offers greater advantages to users of unilateral cochlear implants who have varying residual hearing of the opposite ear.

\section{Objectives}

The present study was to assess speech perception abilities in children using bimodal fitting versus children using cochlear implant alone.

Objectives: (1) The aim is to study and compare the aided thresholds for octave frequencies from 500 to $4,000 \mathrm{~Hz}$ and (2) to study speech perception ability using early speech perception test (ESP) in two conditions: first, children using only unilateral cochlear implant and then bimodal condition. In this study, the relationship between aided thresholds of the nonimplanted side with benefit of bimodal hearing on ESP test and functional performance in children listening through bimodal condition using Parent's Evaluation of Aural/Oral Performance of Children (PEACH) was also done. The relationship between number of years of hearing aid experience and number of hours of hearing aid usage on nonimplanted side with benefit of bimodal hearing on ESP test and PEACH score was also studied.

\section{Materials and Methods}

A detailed case history depicting information related to duration of use of hearing aid, type of hearing aid, programming parameters of hearing aids, and implant age (IA) along with demographic details was collected. Twenty children with varying chronological age from 3 to 8 years with bilateral severe to profound sensorinueral hearing loss were considered for the study. All the children were bimodal listener with varying residuals hearing capacity on the nonimplanted side. All the children were using digital hearing aid with at least four channels, and their hearing aids were suited and programmed as per the their degree of hearing loss. Children who were not able to follow test procedures, children with sensorimotor issues, and mental illness were excluded. A within-subject repeated-measures design, with each subject acting as their own control was used.

Three tests were administered on every participants. First, test was a questionnaire named PEACH scale followed by aided audiogram and ESP test.
- Functional performance of children in day-to-day life was assessed using Marathi version of PEACH questionnaire in an interview manner. PEACH scale has two domains: speech perception in a quite environment and speech perception in the noisy surrounding. Score in percentage for both the domains as well as combined score were recorded. Scoring was done for each question on 0 to 4 scale. Maximum score of the scale was 44 which indicated good listening performance in day-to-day life, while low score indicated poor listening in day-to-day life.

- Aided audiometry was done either by hand raising or play audiometry method in two conditions: (1) CI only and (2) CIHA (bimodal condition). Aided thresholds at $500 \mathrm{~Hz}$, $1 \mathrm{KHz}, 2 \mathrm{KHz}$, and $4 \mathrm{KHz}$ were noted in both the conditions: Testing was performed in air conditioned soundtreated rooms (ANSI S3.1-1991[R-2003]). Calibrated two channel Madson OB-922 with matched sound field speakers was used.

- ESP test in Marathi was utilized for the assessment of speech perception abilities in children with cochlear implant (Sarda and Mathew, 2012). ESP test was administered in two condition, that is, CI only and CIHA (bimodal condition). Stimulus was recorded and played through a loud speakers placed at a 45-degree angle at $1 \mathrm{~m}$ distance. Children were asked to point out picture as per the stimulus presented. Level of presentation was $45 \mathrm{dBHL}$. Scoring was done based on the number of correct responses. Each correct response was given one score while incorrect responses were given zero score. Speech perception scores for monosyllables, bisyllablic, and trisyllabic words as well as pattern perception were noted down. Since all the test procedures required longer time for children to pay attention, 5 to 10 minutes of intervals whenever required was provided to the children. Additionally, to avoid the familiarity effect, the sequence of test presentation-that is monosyllabic, bisyllabic, trisyllabic, and pattern perception-was randomized.

Ethical consideration: Parents were explained about the study in details both verbally and by a printed information sheet. A written consent to participate in the study was taken.

\section{Results}

Data obtained were tabulated, and Statistical Package for Social Sciences software 20.0 was used to carry out the statistical analysis to attain the objectives of the study. The Shapiro-Wilk's test of normality was used to evaluate the normalcy of distribution which revealed $p<0.05$ indicating non-normal distribution of data. Descriptive statistics was applied for the scores of PEACH scale, aided audiometry thresholds, and ESP test.

- PEACH scale: Information was collected from the parents of the children who were listening through bimodal condition in day-to-day life for minimum of 6 to 8 hours, and results are shown in - Table 1 . It can be observed from - Table 1 that overall performance of children in noisy situation is lower compared with quite situation 
Table 1 Mean and standard deviation of Parent's Evaluation of Aural/Oral Performance of Children scale and its domains

\begin{tabular}{|l|l|l|l|}
\hline & Mean & Standard deviation & Number of participants \\
\hline PEACH in quiet & $92.07 \%$ (Max. 100) & $4.46 \%$ & 20 \\
\hline PEACH in noise & $86.00 \%$ (Max. 100) & $8.04 \%$ & 20 \\
\hline PEACH in combined & $88.74 \%$ (Max. 100) & $5.91 \%$ & 20 \\
\hline
\end{tabular}

Abbreviations: Max., maximum; PEACH, Parent's Evaluation of Aural/Oral Performance of Children.

which indicates that even though children were using bimodal listening, there was still difficulty in listening in day-to-day life.

- Aided audiometry test: Descriptive statistics was applied on the data to calculate mean and standard deviation (SD) for the aided thresholds in two conditions, that is, $\mathrm{Cl}$ only and CIHA and is presented in - Fig. 1. It can be seen from - Fig. 1 that there is reduction in the hearing thresholds in the bimodal condition as compared with $\mathrm{CI}$ alone condition, especially at $500 ; 1,000 ; 2,000 \mathrm{~Hz}$; and $4,000 \mathrm{~Hz}$ by 2 to $3 \mathrm{dBHL}$. However, SD values are larger in CIHA condition than $\mathrm{CI}$ alone condition.

- ESP test: Similarly, mean and SD of various domains of ESP test is depicted in - Fig. $\mathbf{2}$ for bimodal and cochlear implant alone condition.

It can be observed in - Fig. 2 that scores on ESP are higher in CIHA condition than $\mathrm{Cl}$ only condition across all the four domains of ESP test. Among all the domains, score was found to be improving maximally in the domain of pattern perception words, monosyllabic word identification followed by bisyllabic and trisyllabic word identification.

Wilcoxon signed-rank test was applied on the data to investigate if there is a statistical significant difference between aided threshold and ESP test results in CI alone and CIHA condition. Results showed statistically significant difference between $\mathrm{CI}$ alone and CIHA condition for aided thresholds at 1,$000 ; 2,000$; and $4,000 \mathrm{~Hz}(p<0.05)$. Similarly, participants performed significantly higher for pattern perception subtest and monosyllabic word identification subtest of ESP in CIHA condition than CI only condition $(p<0.05)$.

To investigate if there is a significant association between aided thresholds of the nonimplanted ear and benefit score on ESP, Kendall's tau-b correlation was used. Benefit score of bimodal condition on ESP test was calculated by subtracting score of ESP in $\mathrm{Cl}$ alone condition from score of ESP in CIHA condition. It was found that there is moderate association between aided thresholds at $4,000 \mathrm{~Hz}$ and benefit of bimodal hearing of pattern perception task and monosyllabic word identification task of ESP test $(r=0.51, p<0.005 ; r=0.55, p<0.02)$.

To study the relationship between years of hearing aid experience and number of hours of hearing aid usage with the benefit of bimodal hearing on ESP test and PEACH score using Kendall's tau-b correlation analysis was applied. Results showed bimodal benefit is not significantly associated with IA, number of years of hearing aid usage before implantation, and number of hours of hearing aid use $(p>0.05)$. Similarly, no significant association $(p<0.05)$ observed between three factors such as IA, numbers of years of hearing aid use, and number of hours of hearing aid use with scores on functional performance in day-to-day life assessed using PEACH scale.

\section{Discussion}

The aim of the current study was to investigate whether children with bimodal hearing devices would derive benefits in speech perception and functional performance more than children using only cochlear implant. Among 20 studied participants, nine children showed bimodal benefit on aided threshold by 5 to $10 \mathrm{~dB}$ at $500 ; 2,000$; and $4,000 \mathrm{~Hz}$. While only six children showed bimodal benefit at 1,000 $\mathrm{Hz}$. Present findings of the benefit of aided thresholds by $10 \mathrm{~dB}$ in nearly $50 \%$ of the studied population is in consensus with earlier studies..$^{5,-10}$ In other words, present study has shown that benefit obtained by hearing aid is not equal

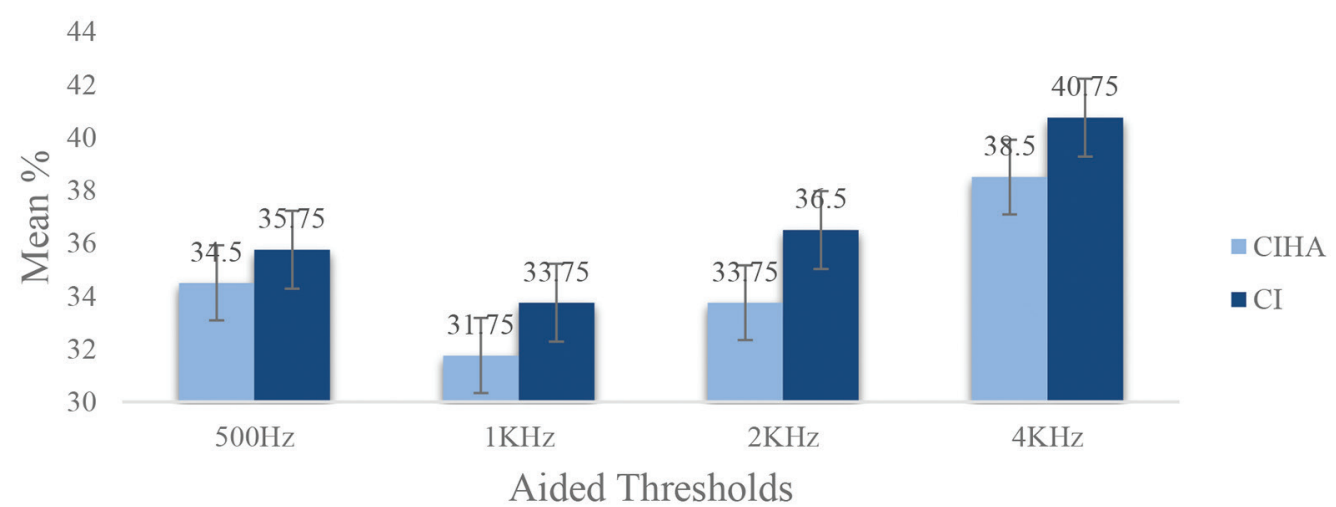

Fig. 1 Mean aided thresholds in cochlear implant and hearing aid ( $\mathrm{ClHA})$ and cochlear implant $(\mathrm{Cl})$ alone condition at octave frequencies. 


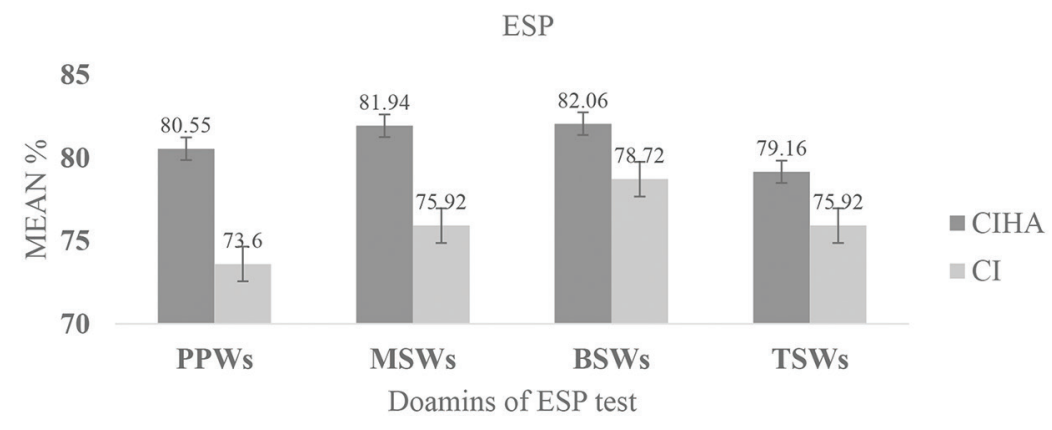

Fig. 2 Mean values of early speech perception test in cochlear implant and hearing aid (CIHA) and cochlear implant (CI) only conditions. BSW, bisyllabic words; MSW, monosyllabic words; PPW, pattern perception words; TSW, trisyllabic words.

among children with severe to profound hearing loss on nonimplanted side. Moreover, benefit is not similar across all octave frequencies even though diagnosis was same across all the children. This can be attributed to the fact that most of the children were diagnosed to have severe to profound hearing loss based on click evoked auditory brainstem response, which does not assess residual hearing at different frequencies above $80 \mathrm{dBHL}$. However, when these children were assessed using visually reinforced audiometry or conditioned play audiometry which could pinpoint their exact residual hearing at different frequencies and then hearing aids were programed based these results more than $50 \%$ of these children were found to have benefit of bimodal advantage.

For studying speech perception, ESP test was administered. Only 18 out of 20 children were able to perform on ESP test. On statistical test, CIHA group performed significantly better than $\mathrm{CI}$ alone group on pattern perception test and monosyllabic words identification task of ESP test. Present reports support the earlier studies by Hua et al who stated that adults with $\mathrm{CI}$ and $\mathrm{HA}$ on the unimplanted ear perform superior than $\mathrm{Cl}$ alone condition. ${ }^{11}$

Additionally, in the present study, it is also noted that benefit was more on pattern perception test and trisyllabic word identification test. This could be due to the fact that pattern perception is much easier to perceive than word identification as a child has to only follow the pattern and respond for the stimulus. Present finding has been also supported by Dunn et al stating that longer stimulus is easier to perceive than shorter stimulus due to temporal integration and more extrinsic cues associated with it. ${ }^{10}$

Furthermore, positive moderate association between aided thresholds at $4,000 \mathrm{~Hz}$ and benefit of bimodal hearing on pattern perception task and monosyllabic word identification task of ESP test was observed. Bimodal benefit has been observed at 1,000; 2,000; and 4,000 Hz. Nevertheless, the association of speech perception using ESP is found only with aided thresholds at $4,000 \mathrm{~Hz}$. This is supported by other investigators-such as Cutler et al, Bonatti et al, and Owren and Cardillo-who have reported that information at high frequency is more important for speech perception than information at mid and low frequency. ${ }^{12-14}$ This would have resulted into stronger association between aided thresholds at $4,000 \mathrm{~Hz}$ with speech perception performance on ESP test among these young children. However, present findings are in contrary to Mok et al who have reported that information provided by the hearing aid at higher frequencies interfere with the speech perception of cochlear Implant. Contradictory finding in the present study could be because in the current study many children had significant hearing benefit at 4,000 $\mathrm{Hz}$ compared with earlier studies by Mok et al who reported few children having any significant benefit of bimodal hearing at $4,000 \mathrm{~Hz}$. Mok et al found significantly positive correlation between bimodal benefit and aided threshold at 1 and $2 \mathrm{KHz}$. At $4 \mathrm{KHz}$, the correlation with bimodal benefit scores were not significantly positive. ${ }^{15}$

Functional performance of children using cochlear implants along with hearing aid was assessed using PEACH scale. It was found that scores on PEACH scale were higher in quite situation as compared with noisy situation. This supports the earlier findings by Gifford et al and Ching et al who have reported that children with cochlear implant perform superior in quite than in noise. ${ }^{8}$

Present finding of no association between number of hours of hearing aid usage with bimodal benefit is supporting the earlier reports of Ching et al, who have stated no significant difference in speech perception performance between individually who use hearing aid for longer versus shorter duration..$^{16}$ However, present results are in contrary to Armstrong et al, (1997) who reported greater binaural benefits for people with better residual hearing and who habitually wore hearing aids for longer time with cochlear implants. ${ }^{7}$ The discrepant findings in the present study could be related to differences in the time since hearing aid has been fitted among the studied population, motivation level of parents etc. If hearing aid and therapy is taken for long time before implantation then children get habituated to hearing aids and then continue to use for longer time irrespective of its benefit. In the current study, there were few children using hearing aid for more than 1 year and few less than 1 year.

Study can be done in future on larger data and using more objective tests such picture identification in noise for pediatric population. If clear correlations are eventually found, 
then guidelines could be established regarding the success or difficulty that may be expected for individuals who receive bimodal stimulation.

\section{Conclusion}

Bimodal hearing is beneficial in most of the children than monaural hearing through cochlear implant.

\section{Conflict of Interest}

None declared.

\section{Acknowledgment}

We would like to thank all the participants of the study and Bharati Vidyapeeth University to allow us to conduct the current study.

\section{References}

1 Silman S, Gelfand SA, Silverman CA. Late-onset auditory deprivation: effects of monaural versus binaural hearing aids. J Acoust Soc Am 1984;76(5):1357-1362

2 Byrne D, Dirks D, Effects of acclimatization and deprivation on non-speech auditory abilities. Ear Hear1996 Doi: 10.1097/00003446-199617031-00004

3 Miller AL. Effects of chronic stimulation on auditory nerve survival in ototoxically deafened animals. Hear Res 2001;151(1-2):1-14

4 Dunn CC, Tyler RS, Witt SA. Benefit of wearing a hearing aid on the unimplanted ear in adult users of a cochlear implant. J Speech Lang Hear Res 2005;48(3):668-680

5 Ching TYC, van Wanrooy E, Hill M, Incerti P. Performance in children with hearing aids or cochlear implants: bilateral stimulation and binaural hearing. Int J Audiol 2006;45(Suppl 1) :S108-S112
6 Gordon KA, Daya H, Harrison RV, Papsin BC. Factors contributing to limited open-set speech perception in children who use a cochlear implant. Int J Pediatr Otorhinolaryngol 2000;56(2):101-111

7 Armstrong M, Pegg P, James C, Blamey P. Speech perception in noise with implant and hearing aid. Am J Otol 1997;18(Suppl 6) :S140-S141

8 Ching TYC, Incerti P, Hill M. Binaural benefits for adults who use hearing aids and cochlear implants in opposite ears. Ear Hear 2004;25(1):9-21

9 Fitzpatrick E, McCrae R, Schramm D. A retrospective study of cochlear implant outcomes in children with residual hearing. BMC Ear Nose Throat Disord 2006;6:7

10 Dunn CC, Perreau A, Gantz B, Tyler RS. Benefits of localization and speech perception with multiple noise sources in listeners with a short-electrode cochlear implant. J Am Acad Audiol 2010;21(1):44-51

11 Hua H, Johansson B, Jönsson R, Magnusson L. Cochlear implant combined with a linear frequency transposing hearing aid. J Am Acad Audiol 2012;23(9):722-732

12 Cutler A, Sebastian-Galles N, Soler-Vilageliu O, Van Ooijen B, Constraints of vowels and consonants on lexical selection: cross-linguistic comparisons. Mem Cogn2000 Doi: 10.3758/ BF03198409

13 Bonatti LL, Peña M, Nespor M, Mehler J. Linguistic constraints on statistical computations: the role of consonants and vowels in continuous speech processing. Psychol Sci 2005;16(6):451-459

14 Owren MJ, Cardillo GC. The relative roles of vowels and consonants in discriminating talker identity versus word meaning. J Acoust Soc Am 2006;119(3):1727-1739

15 Mok M, Galvin KL, Dowell RC, McKay CM. Speech perception benefit for children with a cochlear implant and a hearing aid in opposite ears and children with bilateral cochlear mplants. Audiol Neurotol 2010;15(1):44-56

16 Ching TYC, Psarros C, Hill M, Dillon H, Incerti P. Should children who use cochlear implants wear hearing aids in the opposite ear? Ear Hear 2001;22(5):365-380 